\title{
Overconfidence and the adoption of robo-advice: why overconfident investors drive the expansion of automated financial advice
}

\author{
Dominik M. Piehlmaier ${ }^{*}$ (1)
}

\author{
${ }^{*}$ Correspondence: \\ D.M.Piehlmaier@sussex.ac.uk \\ University of Sussex Business \\ School, University of Sussex, \\ Brighton, UK
}

\begin{abstract}
Adaptive online platforms, powered by artificial intelligence, commonly referred to as robo-advice, steadily increase their market share. Yet these comparably new financial services are critically understudied. Little is known about why some investors adopt robo-advice for something as essential as asset allocation. The current paper tries to close this gap by shedding light on the causal effect of investor overconfidence on the propensity of using robo-advice. The study proposes a theoretical framework that combines the divergence of opinion hypothesis with consumer behavior insights and information technology diffusion research. The framework is empirically tested on the Investor Sample of the 2015 National Financial Capability Study, a subsample of 2000 US investors. The results from a series of generalized linear, structural, and semiparametric models show that in a pre-chasm market, overconfident investors have a significantly higher propensity of adopting robo-advice. While higher financial literacy seems to decrease robo-advice uptake, unjustified confidence in one's knowledge causally increases it. Willingness to take financial risk cannot account for the significantly increased adoption of robo-advice among overconfident investors. The findings help managers to better position robo-advice by offering behavioral insights into their user base. In addition, the results outline a managerial tool to take demand-side actions to increase the likelihood of an end-user innovation crossing the chasm.
\end{abstract}

Keywords: Overconfidence, Robo-advice, Divergence of opinions, Diffusion of innovation

\section{Introduction}

The financial service industry has seen some dramatic changes over the years. Starting as a sector that was defined by personal interaction and a low degree of automation, it saw its first signs of computerization with the introduction of automated teller machines (ATM) in the late 1960s (Woodyard and Grable 2018, 64). This transfer of simple bank clerk responsibilities provided consumers with more autonomy (e.g., being able to withdraw cash after business hours) and allowed banks to expand their service network without opening new branches. The second wave of automation came after the rise of the

(c) The Author(s), 2022. Open Access This article is licensed under a Creative Commons Attribution 4.0 International License, which permits use, sharing, adaptation, distribution and reproduction in any medium or format, as long as you give appropriate credit to the original author(s) and the source, provide a link to the Creative Commons licence, and indicate if changes were made. The images or other third party material in this article are included in the article's Creative Commons licence, unless indicated otherwise in a credit line to the material. If material is not included in the article's Creative Commons licence and your intended use is not permitted by statutory regulation or exceeds the permitted use, you will need to obtain permission directly from the copyright holder. To view a copy of this licence, visit http:// creativecommons.org/licenses/by/4.0/. 
internet (Jung et al. 2018, 82, 83). Banks digitalized services that were previously offered by ATMs as well as clerks and made them available through online banking platforms. This service was later complemented by mobile banking applications. These information technology innovations made banking more convenient for consumers and reduced staffing costs for financial institutions. Both waves of automatization and digitalization have received substantial attention from the research community who assessed the role of consumer behavior in this process (Fain and Roberts 1997).

However, a growing importance of machine learning and artificial intelligence (AI) paved the way for a third wave of automation ( $\mathrm{Du}$ and Xie 2021; Kou et al. 2021). Advanced algorithmic models allow information systems to make limited inferences about situations that are characterized by some degree of uncertainty. This technology was applied to the financial service sector to automate one of its core missions: efficient investment allocations (Abraham et al. 2019). Commonly labeled as robo-advice (also called digital financial advice or online investment advice), these automated wealth management tools allocate and manage investments based on an individual's risk profile and investment goals (e.g., saving for retirement, college funds, etc.) (Jung et al. 2018). The term robo-advice was first introduced during the Great Recession, mainly in order to differentiate it from the legal implications of traditional financial advice (Abraham et al. 2019; Ji 2017). Through substantial economies of scale, the absence of any human interaction, and lower barriers to entry, robo-advisors seem to generate market shares in the segments of millennials and first-time investors with relatively low initial investments (Becchi et al. 2018, 1). Yet there is some evidence that automated wealth management may also attract older investors in their 40s with a higher household income and greater investment capabilities (Kaya 2017, 9).

The discrepancy between a perceived target market and data that illustrate a more nuanced picture, reveals one of the fundamental issues with the status quo of research on robo-advice. A considerable number of publications are industry assessments by private companies that focus on specific markets or strategic issues (Jung et al. 2018, 85, 86). In addition, few studies assess the behavioral component of why investors might use an innovation that saw its first commercial application in 2010, for something as essential as retirement provisions or college fund allocations (Fernandes and Oliveira 2021; Sironi 2016, 22). Also, there is no theoretical explanation for why investors seem to overcome algorithm aversion despite a notable absence of any identifiable control over algorithmic wealth management forecasts (Dietvorst et al. 2018).

There is a growing number of peer-reviewed research on robo-advice (Bhatia et al. 2020; Brenner and Meyll 2020; Lourenço et al. 2020). Yet few available publications shed light on the new IT services from a managerial perspective. Previous research provides descriptive evidence of an average robo-advice user (Belanche et al. 2019; Jung et al. 2018, 84; Lewis 2018; Woodyard and Grable 2018). While they provide insightful information on demographics, risk profiles, and invested assets, the current body of knowledge does not explain why someone would adopt robo-advice but rather describes who uses it. The current paper proposes a theoretical model and empirically tests it to close this gap. There seems to be consensus that robo-advice is a major innovation in finance (Kaya 2017). Yet no theoretical model has been brought forward that combines the rich body of knowledge of financial decision-making with innovation research to explain why 
some investors are willing to invest substantial sums of money, using a relatively novel algorithmic technology (i.e., AI) that they may not fully understand, with start-up companies that have little brand recognition in an industry that used to treat consumer trust as a necessity rather than a bonus (Kaya 2017; Lourenço et al. 2020).

This paper combines insights from the diffusion of innovation theory (DIT) with the divergence of opinion (DOO) hypothesis to theoretically explain why some investors are more likely than others to use robo-advice (Miller 1977; Rogers 2010). The presented evidence goes above and beyond commonly associated demographics (e.g., young age and low income). The proposed model is empirically tested by utilizing information from a representative sample of 2,000 US investors. The results suggest that overconfident investors seem to drive a considerable part of the early expansion of robo-advice in the US. All measures and findings are checked for robustness and causality is derived from a structural model and validated with a nonparametric approach. Lastly, the paper provides insights into the subjective financial consequences of using robo-advice for investors who adopted the online information service.

The remainder of this paper is structured as follows. The next section discusses the literature and provides a theoretical framework. The subsequent paragraphs outline the methodology, including the dataset, measures, missing observations, and stochastic models. This is followed by a presentation as well as a discussion of the results. The paper finalizes with some concluding remarks, managerial implications, and limitations.

\section{Theoretical framework}

The supporting literature can be broadly categorized into four areas: robo-advice, innovation research, overconfidence, and the divergence of opinion. The interconnections are laid out to provide a rationale for the theoretical framework of this paper. The following subsection provides a brief description of robo-advice in the context of innovation research.

\section{Robo-advice as technical innovation}

Robo-advisors are algorithmic wealth management tools. These technical innovations rely on AI to efficiently allocate investments using exchange-traded funds (ETF) and index funds due to their simple cost structure and passive approach to portfolio management (Abraham et al. 2019, 2). Their algorithms conceptualize Markowitz's (1991) portfolio theory and quantify priors based on online investment questionnaires, covering financial goals, risk preferences, investment knowledge, demographics, as well as firmspecific items (e.g., faith-based investments). This process mimics a simplified version of traditional client onboarding through a professional financial advisor (Kaya 2017, 2). Jung et al. (2018, 83 et seq.) structure the procedure for robo-advisors in three phases: client-algorithm alignment, portfolio fitting and customization according to goals and preferences, as well as maintenance. The latter can be used to differentiate automated wealth management tools in either allowing flexible readjustments to individualize the portfolio throughout the life cycle or through a set of predefined products.

The geographic importance of robo-advisors centers in North America. In 2017, more than every other dollar that was invested through robo-advice came from the United States (Burnmark 2017). In addition, the country had by far the largest number of 
robo-advisors with approximately 200 different entities, ranging from small start-ups (i.e., FinTech firms) to major financial institutions, like Bank of America and Wells Fargo (Abraham et al. 2019). European robo-advisors are estimated to account for $5-6 \%$ of the equivalent US share of assets under management (AuM), with approximately $75 \%$ of it coming from the UK (Kaya 2017, 8). A possible explanation for this notable disparity between Continental Europe and the US may be the presence of functioning European welfare systems with centralized retirement schemes and an atypically large asset management industry that does not rely on external automated wealth management tools (ibid., p. 9). Nevertheless, due to the dominance of US robo-advisors, the current paper focuses on US investors to maximize the applicability of the presented results.

Given prior findings, the paper argues that it may be less helpful to ask who is using the financial service innovation but why they are using it. In order to understand the motivation of these investors and, in fact, the market for robo-advice as a whole, it is essential to consider the nature of AI-powered investment advice in the context of technical innovations in finance. One of the largest financial service providers in Europe labeled robo-advice "a true innovation in asset management". More recent studies have also connected innovation research with robo-advisory (Lourenço et al. 2020). However, they do not offer any insight into consumer behavioral aspects regarding the motivation behind using automated wealth management tools.

According to Rogers' (2010, 257 et seq.) seminal work on the diffusion of innovation, innovators and early adopters represent $16 \%$ of all potential users. Rogers characterized the former as risk-takers with high socioeconomic status, while early adopters are coined as trendsetters or influencers with comparably high income and educational attainment. Henceforth, these two groups are called early minority. It is argued that investors who adopted robo-advice are part of this early minority. As of 2019, robo-advisors have reached a market penetration rate of $2.5 \%$ which would suggest that all current users are innovators (Statista Market Forecast 2019). However, financial markets usually follow a different metric, namely assets under management (AuM). In 2018, US-based roboadvisors surpassed the mark of $\$ 400$ billion AuM with an average annual growth rate of $31 \%$ (Abraham et al. 2019, 1). It was anticipated that the sector reaches $10 \% \mathrm{AuM}$ of the overall market by 2020 (Jung et al. 2018, 82). These numbers would suggest that current investors are made up of both innovators and early adopters. Consequently, the remainder of this paper will focus on the early minority to explain why investors might use novel automated wealth management tools for something as essential as their finances.

\section{Overconfidence among innovators and early adopters}

Behavioral researchers have examined the propensity to be excessively confident in one's abilities or knowledge for more than three decades (Markovitch et al. 2015). Coined as overconfidence, it describes the discrepancy between subjective beliefs and objectively measurable outcomes. Previous research has measured overconfidence as the excess between an individual's confidence in one's knowledge on a particular subject matter and the observable performance on a set of questions on that same topic (Ortoleva and Snowberg 2015; Sanchez and Dunning 2018). The finance literature has associated investor overconfidence with other behavioral biases, such as hindsight bias (i.e., the tendency to describe past events as more predictable than what would have been expected at the 
time), self-serving bias (i.e., attributing success to own actions and blaming others or external factors for failure), cognitive dissonance (i.e., avoiding conflicting evidence), and illusion of control (i.e., considering random outcomes as controllable) (Malmendier and Taylor 2015). While the latter is a consequence of an overconfident perception, hindsight bias, self-serving traits, and cognitive dissonance may lead to investor overconfidence.

Intuitively, innovators and early adopters should have a higher propensity to illustrate overconfidence in their abilities. By definition, they invest in new products and services before they reach the mass market. Such investments may carry substantial risks, as evidenced by data from the crowdfunding platform Kickstarter (Yu et al. 2017, 1724). These investors seem overly confident in their ability to predict market success and overestimate the generalizability of their own preferences. Furthermore, the early minority is strongly associated with a higher tolerance towards risk and uncertainty (Rogers 2010, 279). A combination of these two aspects has been shown to highly correlate with overconfidence, especially in finance (Odean 2002).

Prior research on the diffusion of innovation theory (DIT) and overconfidence seems to support this intuition. There is evidence that confidence, rational or otherwise, plays an important role in the adoption and diffusion of innovation (Rogers 2010, 170 et seq.). This begs the question whether overconfidence drives at least some of the early adoption of new technology. O'Neill et al. $(1998,102-105)$ argue that innovators underestimate risks and overestimate returns in an organizational context, leaving them with an overconfident perception regarding their ability to manage innovations. Hirshleifer et al. (2012) seem to confirm this notion and connect overconfident managers in positions of power with a more successful corporate research and development strategy. An experimental study with 330 participants provides further support for these findings (Markovitch et al. 2015). The results also suggest that overconfident individuals overforecast demand for new products. A similar argument can be made regarding a hypothesized overconfidence among early adopters, e.g., among online traders or players in a gametheoretic scenario (Cutler and Staelin 2013; Daniel and Hirshleifer 2015, 66). Lastly, it should be noted that while investor overconfidence has been described as a mainly negative trait, the bias can have positive externalities, such as an increased stock market participation, new business ventures, and, as shown in this paper, a greater likelihood of adopting financial innovations (Daniel and Hirshleifer 2015; Malmendier and Tate 2015; Xia et al. 2014).

\section{Theoretical model and hypothesis}

The previous subsections shed light on why investors might use automated wealth management, the relevant market reach of the online service innovation, and the tendency of its early users to illustrate excessive confidence in their consumer behavior. However, this does not answer the question of why overconfident investors would adopt robo-advice. After all, one might assume that those who think they know more than they actually do would fail to seek financial advice due to precisely those overly confident tendencies. Yet there is little empirical evidence that this argument holds (Kramer 2016). More importantly, however, the subsequent theoretical model does not treat automated wealth management as advice per se, but rather as an innovative financial product. Robo-advisory, despite its name, is not meant to mimic human advice (Ji 2017). The AI-powered service 
is a financial tool to efficiently allocate assets without emotions and investor biases (Bhatia et al. 2020; Brenner and Meyll 2020). It is argued that the novelty of robo-advice and the associated uncertainty regarding reasonable performance expectations drive the adoption of the new service among overconfident investors, not the perception that it could be seen as a form of financial advice.

Aspects of the Divergence of Opinion (DOO) hypothesis are used to explain why the early minority invests through robo-advisors (Al-Nasseri and Menla Ali 2018; Miller 1977). In line with standard financial theory, it is assumed that agents maximize the present value of their investment, with each investor making their best estimate of the expected return. However, due to uncertainty in the system, "potential investors make different estimates of expected returns from the investment" (Miller 1977, 1151, 1152). This divergence of opinion (DOO) increases with risk and uncertainty but narrows over time as the future of robo-advice materializes. Furthermore, Miller hypothesizes that " $a$ badly informed or excessively optimistic small group of investors" drive demand in a market defined by limited supply (pp. 1154, 1166). The current study theoretically argues and empirically shows that this ill-informed or overly optimistic minority consists of overconfident innovators and early adopters who enter the pre-chasm robo-advice market that is characterized by limited relative supply, compared to traditional financial advice because of DOO (Burnmark 2017; Statista Market Forecast 2019).

This theoretical argument can be formalized using Daniel et al. (2018) heterogeneous agents model as a proxy. Their work discusses the effects of overconfidence and the slow diffusion of information on the persistence of mispriced assets. Apart from the standard assumption that in period $t$, agents individually maximize their utility as of period $t+1$, the key component from their model for the current theoretical framework is that there are two types of agents (ibid., Sec. 4). First, there are the early minority agents who initially learn of the financial service innovation (i.e., robo-advice) through primary marketing channels and, to a lesser extent, word of mouth (Rogers 2010, 79 et seq.). These agents receive the signal at the beginning of period $t$ and overreact on it. As per the DOO hypothesis, the current model theorizes that the early minority agents overreact because of a lack of objective knowledge or an excessively high level of perceived knowledge (Miller 1977, 1154). The badly informed or excessively optimistic early minority $(E M)$ agent $i$ forms an expectation in period $t$ of the return $r$ of investing with roboadvice for the following period $t+1, \mathbb{E}_{E M i t}\left[r_{t+1}\right]$. Then, there are mass-market agents who also learn of the innovation in period $t$ but do not act on it due to a perceived lack of information. A mass-market $(M M)$ agent $j$ forms an expectation in period $t$ of the return $r$ of investing with robo-advice for the following period $t+1, \mathbb{E}_{M M j t}\left[r_{t+1}\right]$. Lastly, all "agents believe that their views are correct, and that others will figure that out sooner rather than later", i.e., at the end of period $t+1$, when DOO on the perspective of an investment is assumed to be collectively resolved (Daniel et al. 2018, 24).

The proposed model can be briefly outlined. Without loss of generality, consider a basic utility function $u=\mathbb{E}[r]-\frac{1}{2} A \sigma^{2}$, with $A$ being the constant absolute risk aversion (CARA) coefficient and $\sigma^{2}$ the portfolio variance. In line with the DOO hypothesis, the expected return is the dividing factor between EM and MM agents. Any changes to $A$ or $\sigma^{2}$ that are in line with empirical evidence discussed in Sect. 2 would further elevate the hypothesized effect of an increased adoption rate of robo-advice 
among the overconfident early minority and are, therefore, kept constant for illustration purposes. Let the expected return be a function of overconfidence $o c$ and information $I$ on, e.g., interest rate, past performance, news coverage, etc., that marginally increases over time. The two components essentially replace the more basic perceived probability of a conditional return and conditional returns indicator, respectively. The functional form of the expected return (whether discrete as a sum of products or continuous as an integral) remains unchanged. Since overconfidence is defined as the excess between confidence $c$ and knowledge $K(I)$ (i.e., $o c=c-K(I)$ ), the bias itself is a function of information (Parker and Stone 2014). In particular, it is assumed that confidence starts at an agent-specific level (i.e., intercept) and monotonically increases with knowledge and that the knowledge-deriving process is a standard learning curve, consisting of information and random error (Hall et al. 2007; Spence 1981). In accordance with innovation and marketing research, innovators and early adopters illustrate a higher confidence in an innovation but otherwise start with the same limited information (Moore 2014, 244 et seq.; Rogers 2010, 257 et seq.). In other words, given that information about the online service innovation is initially scarce, and only EM agents are confident enough to act upon the limited signal, $c_{E M i t}>I_{E M i t}$, when they first learn of the novelty at the beginning of period $t$. The reverse is true for MM agents because they are not confident enough to act upon the initial signal as $c_{M M j t} \leq I_{M M j t}$. Therefore,

$c_{E M i t}>c_{M M j t} \wedge I_{E M i t}=I_{M M j t} \Rightarrow o c_{E M i t} \Rightarrow o c_{M M j t} \Leftrightarrow \mathbb{E}_{E M i t}\left[r_{t+1}\right]>\mathbb{E}_{M M j t}\left[r_{t+1}\right] \Rightarrow$ c.p., $u_{E M i t}>u_{M M j t} \forall i, j$

in period t I. Initially, there is DOO when agents first learn of the innovation because EM agents have the same set of information but exhibit higher confidence in the prospect of the new service. They act utility-conform and adopt the innovation. MM agents, on the other hand, do not have the same level of confidence and the given information is not sufficient to outweigh their required risk premium. Consequently, MM agents do not adopt the novelty (or, at least, not at the same rate if a spectrum of different MM agents were to be considered).

The intuition of the model is that innovators and early adopters require little information to act upon. In line with research on the DOT, they invest in new products and services in situations of great uncertainty regarding the future performance and suitability of an innovation because they expect "an order-of-magnitude return on the investment" (Moore 2014, 244). As argued in 2.2, they falsely extrapolate their own preferences to predict mass-market success of an innovation. As per the DOO hypothesis, only the most ill-informed or overconfident investors are willing to invest in such a situation (Miller 1977). At this stage, the average investor remains undecided and requires additional signals (Rogers 2010, 257 et seq.). However, as time passes, more information becomes available, uncertainty as well as risk decrease (partially because of a survivor bias), and the divergence of opinion narrows (Miller 1977, 1155, 1156). The few surviving innovations cross the chasm and reach the mass market (Moore 2014). All remaining disagreements between agents are resolved by the economic forces that shape financial markets.

While the proposed model may be applicable to a wide range of innovations, it is empirically tested in the context of robo-advice. As outlined in the introduction, roboadvice is the latest major innovation in finance (Kaya 2017). Furthermore, automated 
wealth management tools are end-user applications. This aspect reduces statistical noise from institutional investors who may be present in other FinTech areas. Their absence is desirable because private equity managers make investment decisions in an organizational setting with different incentive schemes and utility functions. Consequently, the distinctiveness of the AI-powered technology as a financial service innovation and the resulting applicability of innovation research, its recency, and the clearly defined target group of end-users make robo-advice a promising candidate to test the model. If the theoretical framework holds, overconfident investors should be significantly more likely to adopt robo-advice in a pre-chasm market situation. This leads to the following hypothesis:

H: Overconfident investors have a higher probability to utilize automated financial advice, compared to their calibrated peers in a pre-chasm robo-advice market.

The following section outlines the methodology and describes the data as well as the measures to empirically test the proposed model.

\section{Methods}

The methodology is structured as follows. First, the underlying dataset is summarized, including its source and central tendencies of all utilized variables. Next, the utilization of robo-advice as the main dependent variable, the primary overconfidence measure, as well as a secondary indicator to check its robustness are introduced. All models were fitted in Stata SE 16 with a random seed of 12345 .

\section{Data}

Observations were drawn from the Financial Industry Regulatory Authority's (FINRA) Investor Sample of the National Financial Capability Study (NFCS). The dataset is a publicly available randomized subset of the nationally representative NFCS which was collected in 2015 and published in late 2016 (see Lin et al. 2016 for a complete description of the Investor Sample). The year of data collection guarantees that the investor base of robo-advice had not reached the mass market as the penetration rate was below 1.5\% with $\$ 55$ billion AuM in 2015 (Statista Market Forecast 2019). The dataset is frequently used in financial research studies and its reliability and validity has been extensively tested (Angrisani et al. 2016). The NFCS subsample consists of 2000 active investors who held assets in nonretirement funds with 44.95\% female, median age 55-64, and a median annual household income of $\$ 50,000-\$ 99,999$. Ethnic and racial affiliation were measured with a binary indicator for identifying as non-white/non-Caucasian. Financial risktaking (Q: "When thinking of your financial investments, how willing are you to take risks?") was measured on a 10-point Likert scale, ranging from 1 "not at all willing" to 10 "very willing". No Prediction S\&P500 is a binary indicator for not providing a prediction for the average annual return of the S\&P 500 stock index over the next 10 years (Q: "What do you expect the approximate average annual return of the S\&P 500 stock index to be over the next 10 years (without adjusting for inflation)?"). The central tendencies of all core variables in the dataset are summarized in Additional file 1: Table 1.

Missing data never exceeded 3.85\%. This number is too insignificant to notably bias the reported estimators (Little et al. 2014). Hence, missing observations were listwise 
ignored by default. However, a computationally more demanding approach of multiple imputation chained equation predictive mean matching was applied to check the robustness of this listwise default. All reported results remain virtually unchanged, and the imputation results can be found in the Additional file 1 .

\section{Main dependent variable: robo-advice}

The main dependent variable is a binary indicator for having used robo-advice (Q: "Have you ever used an automated financial adviser that provides investment advice and makes trades on your behalf?"). The majority had not used robo-advice (1,692 investors), 257 answered "Yes", 48 "Don't know", and three "Prefer not to say". These 51 non-substantive responses were listwise ignored as outlined in 3.1. A secondary dependent variable was defined to assess the subjective implications of having used robo-advice. Financial satisfaction (Q: "Overall, thinking of your assets, debts and savings, how satisfied are you with your current personal financial condition?") was measured on a 10-point Likert scale, ranging from 1 ("Not at all satisfied") to 10 ("Extremely satisfied"). The central tendencies are reported in Additional file 1: Table 1; two responded with "don't know" and another two with "prefer not to say".

\section{Main independent variable: IRT overconfidence}

Measuring overconfidence requires further discussion. Overconfidence in one's information or knowledge is defined as the excess between confidence and accuracy of answers in a given subject matter. This would imply that one can simply measure the difference between subjective knowledge (i.e., confidence in one's knowledge) and the sum of correct answers to derive overconfidence (or underconfidence if the difference is $<0$ ). The issue is that this would require both variables, confidence and accuracy, to be drawn from the same or asymptotically similar distributions. This is unlikely to hold, especially when both variables were not measured on the same scale (Parker and Stone 2014). In the NFCS, confidence in one's investment knowledge was measured with a single item (Q: "On a scale from 1 to 7, where 1 means very low and 7 means very high, how would you assess your overall knowledge about investing?") on a 7-point Likert scale; nine respondents did not know and four preferred not to say. Knowledge was assessed with ten investment-related questions (e.g., Q: "Over the last 20 years in the US, the best average returns have been generated by:" A: "Stock", "Bonds", etc. (see Lin et al. 2016, 17 for a full list of questions and answers)). Responses to these ten questions were coded as binary variables, i.e., correct (1), incorrect (0), or missing ("don't know"). Therefore, a deviation measure is unlikely to yield robust results.

A previously proposed approach to solve the issue of a lack of sufficiently identically distributed measures of confidence and knowledge, is to use (among other statistical tools) the properties of ordinary least squares (OLS). If confidence in one's investment knowledge is regressed on knowledge (and its higherorder, e.g., quadratic, cubic, etc., forms), the residual term should accurately capture overconfidence (Ortoleva and Snowberg 2015, 511). This should hold because confidence $_{i}=$ knowledge $_{i}+$ bias $_{i} \Leftrightarrow$ overconfidence $_{i}=$ confidence $_{i}-$ knowledge $_{i}$, especially when bias is estimated using a heteroskedasticity robust approach (EHW), following Eicker (1967), Huber (1967), and White (1980). However, there is another, previously 
understudied issue. The residual method assumes that all investment knowledge questions are equally informative. In other words, it assumes that getting a comparably difficult question wrong is just as important in revealing a person's investment knowledge as answering an easy question incorrectly. In addition, it assumes that all (in this case, ten) questions are sufficiently distinct. For instance, if all ten investment questions center around the issue of stocks, it is questionable whether one can count the number of correct answers to elicit a person's general investment knowledge. Consequently, the necessary assumptions for the residual approach are unlikely to hold.

The current paper proposes a novel method, combining the benefits of the residual approach with an advanced psychometric model to solve these issues. It is suggested that item response theory (IRT) can be utilized to construct a latent knowledge indicator that can be used as a regressor for the residual model. IRT is central to computerized adaptive testing, such as the Graduate Record Examination (GRE), because of the theory's reliability, efficiency, as well as its ability to elegantly handle item-construct-independence (Nguyen et al. 2014, sec. 2). Especially the aspect of independence is crucial to the overconfidence literature because previously employed models (e.g., the residual approach) would assign two different knowledge scores (and consequently two different overconfidence levels) to a respondent who answered first an easy and then a hard set of questions about, say, investment, even though that person's actual subject matter knowledge has not changed at all. IRT accounts for the levels of difficulty and discrimination (i.e., how "different" items are from one another) of questions and assigns individual latent (theta) scores, independent of whether a person answered an easy or a hard test (Embretson and Reise 2013, chap. 1).

Binary IRT are latent variable models with likelihood estimators that come with assumptions. Most notably, unidimensionality (i.e., one, instead of multiple latent variables) and local independence between items after accounting for the latent trait. Prior research suggests that these are justifiable assumptions given the ten utilized knowledge questions (Knoll and Houts 2012). In addition, all participants of the NFCS had the option to state "don't know" which means that no guessing parameter is required. Consequently, a two-parameter IRT (2PL; for location and discrimination, see Nguyen et al. (2014, sec. 2) for an approachable introduction to IRT) was fitted to estimate a person's latent investment knowledge. The results can be found in Additional file 1: Table 2.

The model utilizes all available information, including missing observations. This should be highlighted because it does not require multiple imputation techniques to accurately assess a person's latent investment knowledge. The latent variable was subsequently used to regress confidence in one's investment knowledge (i.e., subjective knowledge) and to derive overconfidence through a fourth-order polynomial in Eq. 1:

$$
\begin{aligned}
\text { confidence }_{i}= & \beta_{0}+\beta_{1} \text { LatentKnowledge }_{i}+\beta_{2} \text { LatentKnowledge }_{i}^{2} \\
& +\beta_{3} \text { LatentKnowledge }_{i}^{3}+\beta_{4} \text { Latentknowledge }_{i}^{4}+\varepsilon_{i}
\end{aligned}
$$

with confidence representing the 7-point confidence indicator, latent knowledge the IRT-derived empirical Bayesian means for theta (henceforth, IRT Knowledge), and $\varepsilon$ the EHW-robust residual overconfidence (henceforth, IRT overconfidence) for participant $i$. The estimated IRT overconfidence variable was standardized for interpretability. The 
central tendencies of the variables are reported in Additional file 1: Table 1. The outcome of the auxiliary regression (i.e., Eq. 1) is reported in Additional file 1: Table 3. Despite the fact that the IRT model is both theoretically as well as methodologically desirable, it may be argued that its validity has not been established. Therefore, the robustness of this overconfidence measure was tested with a secondary indicator that was derived from a residual approach in accordance with Ortoleva and Snowberg (2015). A detailed description of this approach can be found in the Additional file 1.

\section{Results}

The first step is to test the proposed model and the hypothesis that overconfident investors can be associated with a greater propensity of having used robo-advice in 2015, i.e., during a time when the market penetration rate was below 1.5\% (Statista Market Forecast 2019). This would provide strong initial evidence in favor of the proposed model that connects pre-chasm adoption with overconfidence among the early minority to predict the utilization of robo-advice. A probit model with a complete set of control variables and heteroskedasticity-robust standard errors was fitted to shed light on this aspect:

$$
\begin{aligned}
\Phi^{-1}\left({\text { robo } \left.- \text { advice }_{i}\right)=}\right. & \beta_{0}+\beta_{1} \text { IRToverconfidence }_{i}+\beta_{2}{\text { willingness } 2 \text { risk }_{i}+\beta_{3} \text { gender }_{i}} \\
& +\beta_{4} \text { age }_{i}+\beta_{5} \text { bachelorplus }_{i}+\beta_{6} \text { income }_{i}+\beta_{7} \text { married }_{i} \\
& +\beta_{8} \text { ethnic, racialminorit }_{i}+\epsilon_{i}
\end{aligned}
$$

Table 1 summarizes the results. Column (1) shows that, ceteris paribus, higher annual household income and older age are strongly associated with a lower likelihood of having used robo-advice in 2015. This is in line with prior research and matches the perception that wealthier as well as older individuals may be less inclined to use automated investment platforms (Burnmark 2017; Kaya 2017; Woodyard and Grable 2018). Though reassuring, the focus of this paper is to examine the affiliation between overconfidence and the tendency to use robo-advice. The effect is highly significant, even after controlling for an investor's willingness to take financial risk. This ought to be highlighted because, as previously mentioned, a lower-than-average risk aversion might otherwise bias the results and inflate the regressor for overconfidence. Column (2) in Table 1 shows the constant marginal effect sizes for comparison purposes. The finding underlines the theoretical argument that overconfidence is a significant and meaningful predictor for past usage of robo-advice. In fact, excessive confidence in one's knowledge outperforms a person's willingness to take financial risk and is seemingly on par with the effect of income on utilizing automated wealth management. Lastly, one may notice the significant effect of marriage on the propensity of having used robo-advice. Everything else being equal, matrimony seems just as meaningful as risk tolerance in predicting the usage of robo-advice (Table 1, (2)). A possible explanation may be the presence of younger household members, most likely children, who might serve as a proxy for the adoption of new technology among otherwise unlikely investors. This effect has not received scientific attention and may be explored in future studies. The following subsection applies the secondary overconfidence measure to Eq. 2 in order to check the robustness of the presented results. 
Table 1 Probit model estimating pre-chasm usage of robo-advice

\begin{tabular}{|c|c|c|}
\hline Dependent & (1) & (2) \\
\hline Variable: robo-advice & IRT OC probit & Marginal effects \\
\hline \multirow[t]{2}{*}{ IRT overconfidence } & $0.42^{* * *}$ & $0.07^{* * *}$ \\
\hline & $(0.06)$ & $(0.01)$ \\
\hline \multirow[t]{2}{*}{ Willingness to take risk } & $0.15^{* * *}$ & $0.02^{* * *}$ \\
\hline & $(0.03)$ & $(0.00)$ \\
\hline \multirow[t]{2}{*}{ Female } & -0.01 & -0.00 \\
\hline & $(0.09)$ & $(0.01)$ \\
\hline \multicolumn{3}{|l|}{ Age categories } \\
\hline \multirow[t]{2}{*}{$25-34$} & -0.10 & -0.03 \\
\hline & $(0.20)$ & $(0.06)$ \\
\hline \multirow[t]{2}{*}{$35-44$} & $-0.39^{*}$ & -0.10 \\
\hline & $(0.20)$ & $(0.05)$ \\
\hline \multirow[t]{2}{*}{$45-54$} & $-0.83^{* * *}$ & $-0.18^{* * *}$ \\
\hline & $(0.20)$ & $(0.05)$ \\
\hline \multirow[t]{2}{*}{$55-64$} & $-0.88^{* * *}$ & $-0.19^{* * *}$ \\
\hline & $(0.21)$ & $(0.05)$ \\
\hline \multirow[t]{2}{*}{$65+$} & $-1.31^{* * *}$ & $-0.24^{* * *}$ \\
\hline & $(0.22)$ & $(0.05)$ \\
\hline \multirow[t]{2}{*}{ Bachelor or more } & -0.04 & -0.01 \\
\hline & $(0.09)$ & $(0.02)$ \\
\hline \multicolumn{3}{|l|}{ Household income } \\
\hline \multirow[t]{2}{*}{$\$ 50,000-\$ 100,000$} & -0.18 & -0.03 \\
\hline & $(0.12)$ & $(0.02)$ \\
\hline \multirow[t]{2}{*}{$\$ 100,000$ or more } & $-0.52^{* * *}$ & $-0.08^{* * *}$ \\
\hline & $(0.14)$ & $(0.02)$ \\
\hline \multirow[t]{2}{*}{ Married } & $0.19^{*}$ & $0.03^{*}$ \\
\hline & $(0.10)$ & $(0.02)$ \\
\hline \multirow[t]{2}{*}{ Ethnic/racial minority } & 0.17 & 0.03 \\
\hline & $(0.10)$ & $(0.02)$ \\
\hline \multirow[t]{2}{*}{ Constant } & $-1.51^{* * *}$ & \\
\hline & $(0.28)$ & \\
\hline Observations & 1937 & 1937 \\
\hline McFadden's pseudo $R^{2}$ & 0.276 & \\
\hline $\mathrm{BIC}$ & 1201 & \\
\hline $\mathrm{AIC}$ & 1123 & \\
\hline
\end{tabular}

\section{Robustness check: secondary overconfidence measure}

While highly correlated with IRT overconfidence, the secondary measure does not rely on the same stochastic assumptions and is, therefore, a prime candidate to check the robustness of the presented results. Table 2 illustrates the outcome of refitting Eq. 2 with the alternative standardized overconfidence measure (see Additional file 1 for a detailed description). 
Table 2 Probit robustness checks estimating pre-chasm usage of robo-advice

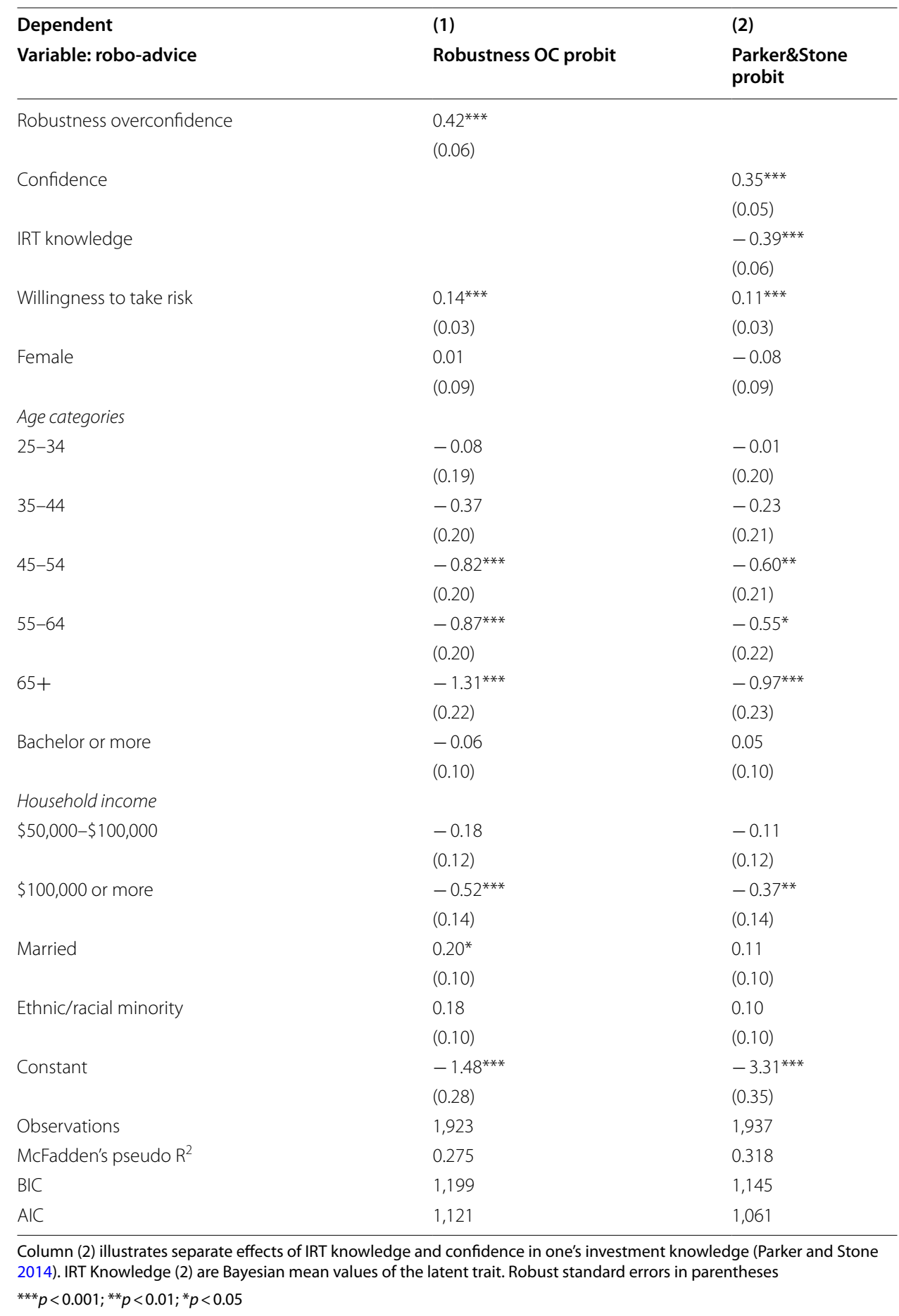

Column (1) supports the initial findings and the hypothesized affiliation between overconfidence and the utilization of AI-powered financial advice. The outcome is virtually identical, both in terms of significance and regression coefficients. A comparison between the reported results and seemingly identical findings, using a naïve 
deviation measure of overconfidence (i.e., confidence - knowledge $=$ overconfidence), can be found in Additional file 1: Table 5.

Despite the empirical evidence, one may question the very nature of the concept of overconfidence (Hill et al. 2014). It could be argued that confidence in one's investment knowledge and investment knowledge are two separate constructs that are fundamentally different (Olsson 2014). The following paragraphs address this concern and shed light on the diverging affiliations between confidence and knowledge with robo-advice.

\section{Robustness check: Parker\&Stone}

Parker and Stone (2014) question the approach of naïve overconfidence measures. They propose separating knowledge as well as confidence and call average residual confidence (i.e., a significant confidence regressor after controlling for knowledge) "unjustified confidence". This critique does not directly affect the reported IRT and residual overconfidence variables in 4.1. Yet the conceptual dispute of treating confidence and knowledge as independent confounders within a system of regressions requires further attention. Thus, the second robustness check was designed to (1) address the theoretical and methodological disagreement as well as (2) isolate the associations of knowledge and confidence with the propensity of having used robo-advice in a pre-chasm market.

Column (2) in Table 2 summarizes the findings. After controlling for investment knowledge, confidence in one's subject matter knowledge remains highly significant. Contrary to previous research, higher investment knowledge seems to have a negative relation with the usage of robo-advice (Woodyard and Grable 2018). However, this finding is very much in line with the DOO hypothesis and the proposed theoretical model in this paper that only the most ill-informed and excessively confident investors would invest in an online service innovation that comes with a high level of uncertainty regarding a reasonable expected return (Miller 1977). The outcome shows a consistent and highly significant presence of what Parker and Stone labeled "unjustified confidence". All other implications and associations remain unchanged to previous models.

Lastly, it should be noted that McFadden's Pseudo R², Bayesian (BIC) and Akaike (AIC) information criteria suggest a somewhat superior model fit of the Parker\&Stone probit link. The central model in Table 1 and the robustness check applying a residual overconfidence indicator are indistinguishable in terms of their goodness of fit (McFadden 1974; Posada and Buckley 2004). In conclusion, overconfidence remains a highly significant and meaningful regressor for the usage of robo-advice, independent of its conceptualization or measurement. These findings strongly support the hypothesized affiliation and the theorized omnipresence of overconfidence among the early minority of robo-advice users in a pre-chasm market.

\section{Causality check}

Despite the fact that Tables 1 and 2 illustrate a coherent picture, the models cannot claim a causal interaction between overconfidence and robo-advice. One might say that the results are driven by causal selection (i.e., reversed causality). A plausible argument would be that unobserved prior usage of robo-advice led to increases in financial returns 
(likely due to the more favorable fee structure) which, in turn, inflated an investor's ego and resulted in an illusion of high (subjective) investment knowledge. This line of reasoning would assume that it is unlikely that objectively measurable investment knowledge would increase solely because someone uses a fully automated wealth management tool. Therefore, the difference between subjective and objective investment knowledge might be driven by the usage of robo-advice, not vice versa.

One way to test this conflicting hypothesis would be to design a randomized controlled experiment. However, modeling an expanding market for a new financial service would require several simplifications that undermine the external validity of a study aiming to empirically assess a theoretical model. Consequently, a structural approach was chosen to examine the causality of the presented finding. Specifically, a simultaneous equation generalized probit model was fitted to solve the issue of causal selection (Amemiya 1978). The approach is essentially a generalized linear instrumental variable (IV) model using a likelihood estimator. Formally, this instrument needs to satisfy the same requirements that were conceptualized for a simple two-stage least square IV model (Wooldridge 2010, chap. 5.1).

The instrument under consideration is a binary indicator for whether an investor was willing to provide an estimate for the average annual return of the S\&P 500 over the next ten years; "don't know" responses were coded as 1 . This IV elicits metaknowledge (i.e., knowledge about one's knowledge and its limits), a concept that has been associated with lower levels of overconfidence (Malmendier and Taylor 2015). Specifically, people with higher metaknowledge seem to be less likely to express excessive confidence because they are aware of the limits of their knowledge. However, providing or not providing an estimate for the average annual return, should not relate to the propensity of having used robo-advice, beyond its implications for overconfidence. In other words, apart from the metaknowledge component that influences overconfidence, there seems to be no conceptual link between automated financial advice and the willingness to provide a performance estimate $(r=-0.13)$. The exact nature of the question is not the primary focus of this instrumental approach as metaknowledge does not and should not measure objective knowledge. Instead, a reliable metaknowledge indicator should be theoretically related to the overconfidence measure (here, both are about investment), offer a way to express metaknowledge (here, "don't know" option), and be of high perceived difficulty to provide an opportunity to reflect on one's knowledge (here, $56 \%$ of all sampled investors were unable to correctly answer at least half of the 10 investment literacy questions and should find it comparably hard to predict the average annual return of the S\&P 500 over such a long time span) (Lin et al. 2016, 18). Methodologically, the IV behaves as expected and negatively correlates $(r=-0.30)$ reasonably well with IRT overconfidence. The F-statistic of the first stage linear equation is 70.39. This vastly exceeds the somewhat arbitrary threshold of $\mathrm{F}<10$ for weak instruments (Stock and Yogo 2002). Therefore, the auxiliary hypothesis that the proposed instrument is weak can be comfortably rejected. All these aspects provide evidence that the selected instrument may be appropriate to address the causal link between overconfidence and robo-advice. Equation 3 conceptualizes the first-stage linear equation of the structural model: 
Table 3 Generalized linear instrumental variable model and first stage equation

\begin{tabular}{|c|c|c|}
\hline & (1) IRT OC & (2) Robo-advice \\
\hline No prediction S\&P500 & $\begin{array}{l}-0.53^{* * *} \\
(0.06)\end{array}$ & \\
\hline Fitted IRT overconfidence & & $\begin{array}{l}0.75^{* *} \\
(0.24)\end{array}$ \\
\hline Willingness to take risk & $\begin{array}{l}0.15^{* * *} \\
(0.01)\end{array}$ & $\begin{array}{l}0.08 \\
(0.06)\end{array}$ \\
\hline Female & $\begin{array}{l}-0.17^{* * *} \\
(0.04)\end{array}$ & $\begin{array}{l}0.07 \\
(0.10)\end{array}$ \\
\hline \multicolumn{3}{|l|}{ Age categories } \\
\hline $25-34$ & $\begin{array}{l}-0.04 \\
(0.12)\end{array}$ & $\begin{array}{l}-0.07 \\
(0.19)\end{array}$ \\
\hline $35-44$ & $\begin{array}{l}-0.09 \\
(0.12)\end{array}$ & $\begin{array}{l}-0.32 \\
(0.21)\end{array}$ \\
\hline $45-54$ & $\begin{array}{l}-0.14 \\
(0.12)\end{array}$ & $\begin{array}{l}-0.72^{* *} \\
(0.23)\end{array}$ \\
\hline $55-64$ & $\begin{array}{l}-0.08 \\
(0.12)\end{array}$ & $\begin{array}{l}-0.79^{* * *} \\
(0.23)\end{array}$ \\
\hline $65+$ & $\begin{array}{l}-0.10 \\
(0.12)\end{array}$ & $\begin{array}{l}-1.19^{* * *} \\
(0.26)\end{array}$ \\
\hline Bachelor or more & $\begin{array}{l}-0.04 \\
(0.04)\end{array}$ & $\begin{array}{l}-0.03 \\
(0.09)\end{array}$ \\
\hline Household income & & \\
\hline$\$ 50-\$ 100 \mathrm{~K}$ & $\begin{array}{l}0.05 \\
(0.06)\end{array}$ & $\begin{array}{l}-0.20 \\
(0.11)\end{array}$ \\
\hline$\$ 100 \mathrm{~K}$ or more & $\begin{array}{l}0.16^{*} \\
(0.06)\end{array}$ & $\begin{array}{l}-0.56^{* * *} \\
(0.13)\end{array}$ \\
\hline Married & $\begin{array}{l}0.04 \\
(0.05)\end{array}$ & $\begin{array}{l}0.17 \\
(0.10)\end{array}$ \\
\hline Ethnic/racial minority & $\begin{array}{l}0.14^{* *} \\
(0.05)\end{array}$ & $\begin{array}{l}0.11 \\
(0.11)\end{array}$ \\
\hline Constant & $\begin{array}{l}-0.82^{* * *} \\
(0.14)\end{array}$ & $\begin{array}{l}-1.11^{* *} \\
(0.43)\end{array}$ \\
\hline Observations & 1,937 & 1,937 \\
\hline
\end{tabular}

Column (1) illustrates the first stage in Eq. 3. Robust standard errors in parentheses. Z-score of "No Prediction S\&P 500" equals -8.39 . Column (2) is a simultaneous equation generalized probit model, replacing IRT OC with its estimated values from the first stage

${ }^{* * *} p<0.001 ;{ }^{* *} p<0.01 ;{ }^{*} p<0.05$

$$
\begin{aligned}
& \text { IRToverconfidence }_{i}= \pi_{0}+\pi_{1} \text { NoPredictionS\&P500 }_{i}+\pi_{2}{\text { willingness } 2 \text { risk }_{i}+\pi_{3} \text { gender }_{i}} \\
&+\pi_{4} \text { age }_{i}+\pi_{5} \text { bachelorplus }_{i}+\pi_{6} \text { income }_{i}+\pi_{7} \text { married }_{i} \\
&+\pi_{8} \text { ethnic, racialminority } \\
&
\end{aligned}
$$

Column (1) of Table 3 summarizes the outcome. The estimation results are in line with prior research on overconfidence. Willingness to take financial risk is positively associated with excessive confidence in one's investment knowledge (Daniel and Hirshleifer 2015). Similar observations can be made regarding individuals in the highest annual household income group and investors who self-identify as being part of an ethnic or racial minority (Bhandari and Deaves 2006). Females, on the other hand, are less likely 
to be overconfident (Ortoleva and Snowberg 2015). While these findings are reassuring, the most important outcome is the significantly negative affiliation of the unwillingness to provide a prediction of the S\&P 500 average annual performance over the next 10 years with overconfidence. This supports the validity of the estimation results in Column (2).

The generalized linear model (Table 3 (2)) strongly suggests that the fitted overconfidence estimates remain significant even after potential endogeneity of the construct has been accounted for. All other implications regarding old age and high household income continue to hold. One may notice that the willingness to take financial risk lost its significance. This may be related to an error rate inflation (i.e., higher standard errors) in these structural models (Wooldridge 2010, chap. 5.1). Lastly, it should be stressed that a Wald test of exogeneity $\left(\chi^{2}(1)=1.50 \Leftrightarrow p>0.22\right)$ fails to reject the auxiliary hypothesis that IRT overconfidence is an exogenous variable. Strictly speaking, there is no formal evidence that the procedure in 4.3 is even required as there might not be any endogeneity issue between the chosen overconfidence measure and robo-advice. That said, it is determined that there is a theoretical rationale for thoroughly addressing potential causal issues. Results in Additional file 1: Table 6 were derived from the same structural approach, treating confidence (instead of overconfidence) as endogenous and controlling for knowledge. Overconfidence (or unjustified confidence) continues to significantly increase the likelihood of using robo-advice. The next subsection sheds light on the robustness of the causal findings.

\section{Robustness of causality}

An issue with structural models is that they rely on a number of parametric assumptions. An alternative way to approach causal inference is through nonparametric matching functions to compare differences in outcome means between sufficiently similar individuals who received or did not receive a predefined "treatment" (Abadie et al. 2004). A binary variable is required in order to estimate average treatment effects of overconfidence on the propensity of having used robo-advice in a pre-chasm market, applying a nearest neighbor matching function (Imbens 2004). Thus, investors were separated into low (51.18\%) and high IRT overconfidence groups by utilizing a median split. The distance metric for the matching function followed a Mahalanobis invert sample covariate covariance (De Maesschalck et al. 2000).

Exact matches were required for annual household income and age due to their theoretical as well as empirical importance (see Tables $1,2,3$ ). The three income and cumulative age categories (Additional file 1: Table 1) were used to account for it. In addition, willingness to take financial risk, gender, educational attainment, marital status, and ethnicity/race were used for approximate similarity. All stated variables were bias-adjusted to account for a large sample size and heteroskedasticity-robust standard errors were applied. The average treatment effect of illustrating above-average overconfidence in one's investment knowledge on using robo-advice is 9.27\% (robust standard error (rSE) $1.63 \% ; p<0.0001$, 95\% Confidence Interval (CI) [6.07\%; 12.47\%]). In other words, being excessively confident increases the use of robo-advice by an average of $9.27 \%$ for all investors. The distance measure seems normally distributed, ranging from -1.07 to 1.09 with a standard deviation (SD) of 0.38. In summary, the outcome of a nonparametric 
matching exercise to estimate the average treatment effect of overconfidence on the population strongly supports the notion that excessive confidence causally increases the likelihood of using robo-advice. All previously reported findings seem to support the proposed theoretical model of an overconfident early minority that drives the usage of automated wealth management tools in a pre-mass-market situation.

\section{Implications for financial satisfaction}

Researchers have associated investor overconfidence with a number of suboptimal financial outcomes and behavioral traits, for instance, excessive trading, stock picking, a lack of diversification, or failure to seek financial advice (Daniel and Hirshleifer 2015; Lewis 2018). Thus, one may wonder whether overconfidence-driven adoption of automated wealth management hurts investors. While it is not the primary focus of the current paper to provide a definite answer to this question, mimicking the previously applied approach of nearest neighbor matching to calculate average treatment effects may shed light on a consumer behavioral aspect of choosing vs not choosing to adopt robo-advice from a proposed utility standpoint.

The variable of interest is satisfaction with one's personal financial situation, measured on a 10-point scale. This is an arguably crude proxy for an agent's utility, but it offers some insight into an investor's perceived financial situation. Treatment is defined to be the binary robo-advice variable with exact matches for age and income. All other covariates remain identical to previous models, except for IRT overconfidence which was added to the list (and bias-adjusted along with all other variables). The average treatment effect on the population is insignificant (coefficient 0.12; rSE 0.16; $p>0.45$; $95 \%$ CI $[-0.19 ; 0.43])$. There is no evidence that using robo-advice would have led to higher subjective financial satisfaction among all investors. This is a promising first step as it indicates that mass-market agents seem to behave utility-conform by not adopting robo-advice in a pre-chasm market, as assumed by the model. The next step is to test whether having used robo-advice in or before 2015 had an impact on the early minority's financial satisfaction. If only users of the technological innovation are assessed (i.e., the average treatment effect on the treated), an additional layer of empirical support for the model unfolds (Imbens 2004). Compared to a counterfactual scenario in which no investor had adopted the technology, robo-advice users experienced a modest but statistically significant increase in financial satisfaction by about 5\% (coefficient 0.46; rSE 0.20; $p<0.019 ; 95 \%$ CI [0.08; 0.84]; distance measure ranging from -7.54 to 8.96 with 2.65 $\mathrm{SD})$. This suggests that, in line with the model predictions, automated wealth management tools positively impacted the satisfaction levels of early minority agents who chose to use the innovation in a pre-chasm market situation. This may indicate some form of utility-conform behavior among innovators and early adopters of robo-advice.

\section{Discussion}

In accordance with prior research, old age seems to be the strongest predictor for not adopting robo-advice. After all, investors at or close to retirement age are not poised to be opinion leaders for an AI-powered financial innovation (Moore 2014; Rogers 2010, 89 et seq.). In addition, some sort of wealth management has already been established at that point in life. Similarly, retirement provisions and college fund allocations are 
less important once an investor retires or is close to retirement age. Furthermore, roboadvice solely relies on online platforms and mobile applications require a certain level of internet affinity and trust in technological advances (Dietvorst et al. 2018). Both of these aspects may be diminished among older investors (Lourenço et al. 2020). However, the notion that only highly educated but financially strained millennials use roboadvice cannot be confirmed by the presented findings. Instead, ceteris paribus, investors between 35 and 44 are not significantly different in their adoption of AI-powered financial advice, compared to the baseline group of digital natives. Likewise, higher educational attainment seems to be unrelated to robo-advice. In fact, when confidence and investment knowledge are assessed separately (Table 2(2)), higher objective investment knowledge can be associated with a lower likelihood of having used robo-advice, as predicted by the current model. While income does seem to play a role in this process, it only significantly matters for annual household incomes of $\$ 100,000$ and more.

All these aspects indicate that previously associated demographics may not be the best predictors for the adoption of robo-advice. Instead, the current paper proposes a theoretical model that outlines who and, more importantly, why investors adopt roboadvice. It empirically shows that those who used the innovation less than five years after the very first commercial application was launched in 2010, and before most major US banks invested in the technology, share a much more meaningful behavioral trait (Abraham et al. 2019). They are, on average, overconfident in their investment knowledge. This is in line with research in finance and innovation and strongly supports the theory that early users of the novel tool do so, at least in part, because they are overconfident which materializes in a divergence of opinion among investors (Daniel and Hirshleifer 2015; Hirshleifer et al. 2012; Markovitch et al. 2015; Miller 1977). In addition, overconfidence consistently outperforms an investor's willingness to take financial risk in terms of its predictability to adopt robo-advice. This is meaningful insofar as it supports the theoretical assumption that overconfidence and its impact on expected returns drive the adoption of the innovation among the early minority rather than the fact that they seek or shy away from the financial risk of investing in robo-advice. In a pre-chasm market that is defined by DOO, these investors seem to act utility-conform as they expect higher returns from investing in the innovation compared to mass-market users. Causally traceable increases in subjective financial satisfaction among early users of roboadvice might underline these theoretically assumed positive effects on an EM investor's utility function.

The current paper offers two distinct contributions to innovation research. First, it offers novel insights through a combination of the DOO hypothesis and the DIT to conceptually explain and empirically test why some investors are more likely to use robo-advice than others. Early robo-advice users seem excessively confident in their investment knowledge. They may believe that their information is more precise than it actually is, overestimating future demand of the financial innovation, and underestimating the impact of individual preferences and market uncertainty (Markovitch et al. 2015; Miller 1977). The theory of an overconfident early minority may be more widely applicable and could potentially close an important gap in the innovation literature. Namely, the notable absence of tangible managerial measures that can be taken to increase the likelihood of a mass-market success of a financial innovation by taking demand-side actions 
through targeted marketing efforts to reach overconfident users. This could help to cross the chasm and decrease DOO. In addition, this paper combines Miller's (1977) DOO with insights from Daniel et al. (2018) as well as from Daniel and Hirshleifer (2015) to provide a theoretical rationale for why some investors adopt robo-advice in a pre-chasm market while others stay on the sideline. Given that proposed theoretical framework can be applied to financial innovations more widely, the current paper also contributed to the diffusion of innovation theory in finance.

Apart from scientific contributions, the current study has several managerial implications. The success of robo-advice crucially depends on growing market shares, relative to professional financial advisors (Burnmark 2017). A larger investor base decreases average cost due to economies of scale (Kou et al. 2021). Additionally, growth increases word-of-mouth advertising which supports and accelerates the diffusion of automated wealth management tools (Agnew and Mitchell 2019, chap. 10; Moore 2014). Given the omnipresence of overconfidence among investors and gamblers, the findings of this study can be used to create targeted online campaigns to directly address overconfident investors, e.g., on online poker or betting sites (Goodie 2005; Merkle 2017; Tse et al. 2004). These investors have a higher likelihood of utilizing robo-advisors, seemingly independent of educational attainment, gender, or ethnicity/race. In fact, it seems likely that overconfident investors would disproportionately benefit from automated financial advice beyond their expected return and perceived financial satisfaction. Automated wealth management tools prevent, or at least complicate, excessive financial behavior, such as overtrading and stock picking (Kaya 2017). Both of these traits have been associated with financial overconfidence (Daniel and Hirshleifer 2015).

Similarly, insights from this study can be used to increase marketing efforts and outreach to underprivileged investors. Lower financial knowledge seems to be strongly associated with the use of robo-advice, at least among the early minority. Therefore, basic financial literacy courses in community colleges or high schools might offer a platform to market robo-advice to investors who would otherwise be hard to reach. In this case, algorithmic advice could level the playing field between highly educated and less educated investors to gain access to competitive wealth management tools. Lastly, investors who self-identify as being part of an ethnic or racial minority seem just as likely to use robo-advice as white/Caucasian individuals. Investors who would feel underrepresented in the financial service sector could benefit from automated and objective advice (Lusardi and Mitchell 2007).

\section{Limitations and future directions}

The generalizability of the presented findings is constrained by a number of factors. Though nationally representative, some or all effects may be limited to the NFCS Investor Sample. Replication and cross-validation of the models are strongly encouraged and actively supported. Future research should include primary data to test the validity of the proposed theoretical framework. Future studies could also explore how the theory of cognitive dissonance or opinion dynamics impact the proposed theoretical model (Zha et al. 2021). Second, overconfidence was conceptualized in terms of excessive confidence in one's investment knowledge. However, the bias has been shown to be highly domainspecific (Muthukrishna et al. 2014). Thus, it cannot be concluded that all innovators and 
early adopters are overconfident, without validating the proposed model industry-byindustry. Third, the quantity and quality of investment knowledge questions were predefined by the NFCS. Even though every effort in terms of robustness checks and measure deviations had been made to account for this shortcoming, a more psychometrically balanced set of questions might reveal a more complex interaction between investment knowledge, confidence, and robo-advice. Researchers and panel companies might want to consider including a combination of various established investment question batteries in order to bypass this issue. Lastly, it may be possible that some of the 2,000 active US investors did not think (or know) that "an automated financial adviser" represents robo-advice. This might skew the results if a substantial number of investors gave falsepositive or false-negative responses. However, rather than assuming that they blindly and somehow consistently responded with "yes" or "no" to a question that they may not understand, a more likely scenario would be that these investors gave non-substantive responses (i.e., "don't know"/"prefer not to say"). In fact, $2.55 \%$ of all respondents fall into this non-substantive category. The reported results do not rely on these responses and the number is too small to skew any prediction. However, even if they are accounted for by advanced semiparametric modeling (i.e., multiple imputation chain equation predictive mean matching), the results are virtually identical (see Additional file 1: Table 4).

\section{Conclusion}

Shedding light on the motivation behind an investor's decision to adopt robo-advice is critical in understanding why automated financial advice crossed the chasm while other financial innovations fail to reach the mass market. This paper provides a theoretical framework, arguing that investors with the highest confidence in their financial knowledge or their least informed but sufficiently confident peers act on signals despite limited information. Driven by their overconfidence, these investors expect higher returns than less overconfident mass market investors and, hence, adopt robo-advice in a pre-chasm market. The presented empirical findings consistently support this theory though the generalizability of these outcomes for other financial innovations remains to be assessed by future research.

\section{Supplementary Information}

The online version contains supplementary material available at https://doi.org/10.1186/s40854-021-00324-3.

Additional file 1. Supplementary Information and Results.

Acknowledgements

The author would like to thank Stefan Zeisberger, Jianying Qiu, and other participants of the Nijmegen Finance Research Seminar as well as David Weiss and the participants of the 57th Bayesian Research Conference for their helpful comments on an earlier version of this manuscript. The author is grateful for the input from the editor and the reviewers.

Authors' contributions

The author individually analyzed the data, reported the results, wrote all drafts, and revised the final manuscript. The author read and approved the final manuscript

\section{Funding}

None.

Availability of data and materials

The data that support the findings of this study are available from the Financial Industry Regulatory Authority under: https://www.usfinancialcapability.org/downloads/NFCS_2015_Inv_Data_Excel.zip. The survey and instruments can be found under: https://www.usfinancialcapability.org/downloads/NFCS_2015_Inv_Qre.pdf. 


\section{Declarations}

Competing interests

The author declares to have no competing interests.

Received: 4 October 2021 Accepted: 12 December 2021

Published online: 09 February 2022

\section{References}

Abadie A, Drukker D, Herr JL, Imbens GW (2004) Implementing matching estimators for average treatment effects in Stata. Stata J Promot Commun Stat Stata 4(3):290-311. https://doi.org/10.1177/1536867X0400400307

Abraham F, Schmukler SL, Tessada J (2019) Robo-advisors: investing through machines. World Bank policy research working paper, no. 134881

Agnew J, Mitchell OS (2019) The disruptive impact of FinTech on retirement systems. Oxford University Press

Al-Nasseri A, Ali FM (2018) What does investors' online divergence of opinion tell us about stock returns and trading volume? J Bus Res 86(May):166-178. https://doi.org/10.1016/j.jbusres.2018.01.006

Amemiya T (1978) The estimation of a simultaneous equation generalized probit model. Econometrica 46(5):1193-1205. https://doi.org/10.2307/1911443

Angrisani M, Kapteyn A, Lusardi A (2016) The national financial capability study: empirical findings from the American Life Panel Survey. FINRA report, 43

Becchi S, Hamaloglu U, Aggarwal T, Panchal S (2018) The evolution of robo-advisors and advisor 2.0 model. EY. https:// www.ey.com/Publication/vwLUAssets/ey-the-evolution-of-robo-advisors-and-advisor-2-model/\$FILE/ey-the-evolu tion-of-robo-advisors-and-advisor-2-model.pdf

Belanche D, Casaló LV, Flavián C (2019) Artificial intelligence in FinTech: understanding robo-advisors adoption among customers. Ind Manag Data Syst 119(7):1411-1430. https://doi.org/10.1108/IMDS-08-2018-0368

Bhandari G, Deaves R (2006) The demographics of overconfidence. J Behav Financ 7(1):5-11. https://doi.org/10.1207/ s15427579jpfm0701_2

Bhatia A, Chandani A, Chhateja J (2020) Robo advisory and its potential in addressing the behavioral biases of investorsa qualitative study in Indian context. J Behav Exp Financ 25(March):100281. https://doi.org/10.1016/j.jbef.2020. 100281

Brenner L, Meyll T (2020) Robo-advisors: a substitute for human financial advice? J Behav Exp Financ 25(March):100275. https://doi.org/10.1016/j.jbef.2020.100275

Burnmark (2017) Digital wealth. https://www.burnmark.com/uploads/reports/Burnmark_Report_Apr17_Digital_Wealth. pdf

Cutler J, Staelin R (2013) When it pays to think about the competition, and when it doesn't: exploring overconfidence bias in dynamic games. Contrib Game Theory Manag 6:75-88

Daniel K, Klos A, Rottke S (2018) Overconfidence, information diffusion, and mispricing persistence. Working paper 25346. Working paper series. National Bureau of Economic Research. https://doi.org/10.3386/w25346

Daniel KD, Hirshleifer D (2015) Overconfident investors, predictable returns, and excessive trading. J Econ Perspect 29(4):61-88. https://doi.org/10.1257/jep.29.4.61

De Maesschalck R, Jouan-Rimbaud D, Massart DL (2000) The mahalanobis distance. Chemom Intell Lab Syst 50(1):1-18. https://doi.org/10.1016/S0169-7439(99)00047-7

Dietvorst BJ, Simmons JP, Massey C (2018) Overcoming algorithm aversion: people will use imperfect algorithms if they can (even slightly) modify them. Manag Sci 64(3):1155-1170. https://doi.org/10.1287/mnsc.2016.2643

Du S, Xie C (2021) Paradoxes of artificial intelligence in consumer markets: ethical challenges and opportunities. J Bus Res 129(May):961-974. https://doi.org/10.1016/j.jbusres.2020.08.024

Eicker F (1967) Limit theorems for regressions with unequal and dependent errors. In: Proceedings of the fifth Berkeley symposium on mathematical statistics and probability, vol 1, pp 59-82. https://books.google.com/books?hl=en\& $|r=\& i d=| C 4 K u \_7 d B F U C \& o i=f n d \& p g=P A 59 \& d q=\% 22$ however, + the + assumptions +of +\%5B9\%5D+are+more+ restrictive+than+those+of\%22+\%22(r.v.\%27s)+about+which+we+assume+throughout $\% 22+\% 22$ to +be+ normalized+by+premultiplication+by+certain+matrices+Bn.\%22+\&ots=nOSil019qO\&sig=37eRSCVS_aQPTZ akVncSeZWlcGk

Embretson SE, Reise SP (2013) Item response theory. Psychology Press

Fain D, Roberts ML (1997) Technology vs. consumer behavior: the battle for the financial services customer. J Direct Mark 11(1):44-54

Fernandes T, Oliveira E (2021) Understanding consumers' acceptance of automated technologies in service encounters: drivers of digital voice assistants adoption. J Bus Res 122(January):180-191. https://doi.org/10.1016/j.jbusres.2020. 08.058

Goodie AS (2005) The role of perceived control and overconfidence in pathological gambling. J Gambl Stud 21(4):481502. https://doi.org/10.1007/s10899-005-5559-1

Hall CC, Ariss L, Todorov A (2007) The illusion of knowledge: when more information reduces accuracy and increases confidence. Organ Behav Hum Decis Process 103(2):277-290. https://doi.org/10.1016/j.obhdp.2007.01.003

Hill AD, Kern DA, White MA (2014) Are we overconfident in executive overconfidence research? An examination of the convergent and content validity of extant unobtrusive measures. J Bus Res 67(7):1414-1420. https://doi.org/10. 1016/j.jbusres.2013.08.011

Hirshleifer D, Low A, Teoh SH (2012) Are overconfident CEOs better innovators? J Financ 67(4):1457-1498. https://doi.org/ 10.1111/j.1540-6261.2012.01753.x 
Huber PJ (1967) Under nonstandard conditions. In: Proceedings of the fifth Berkeley symposium on mathematical statistics and probability: weather modification, vol 5, 221 p. Univ of California Press

Imbens GW (2004) Nonparametric estimation of average treatment effects under exogeneity: a review. Rev Econ Stat 86(1):4-29. https://doi.org/10.1162/003465304323023651

Ji M (2017) Are robots good fiduciaries: regulating robo-advisors under the investment advisers act of 1940. Colum Law Rev 117:1543

Jung D, Dorner V, Glaser F, Morana S (2018) Robo-advisory. Bus Inf Syst Eng 60(1):81-86. https://doi.org/10.1007/ s12599-018-0521-9

Kaya O (2017) Robo-advice-a true innovation in asset management. Deutsche Bank Research, August. https://www. dbresearch.com/PROD/DBR_INTERNET_EN-PROD/PROD0000000000449010/Robo-advice_-_a_true_innovation_in_ asset managemen.pdf

Knoll MAZ, Houts CR (2012) The financial knowledge scale: an application of item response theory to the assessment of financial literacy. J Consum Aff 46(3):381-410. https://doi.org/10.1111/j.1745-6606.2012.01241.x

Kou G, Akdeniz ÖO, Dinçer H, Yüksel S (2021) Fintech investments in European banks: a hybrid IT2 fuzzy multidimensional decision-making approach. Financ Innov 7(1):39. https://doi.org/10.1186/s40854-021-00256-y

Kramer MM (2016) Financial literacy, confidence and financial advice seeking. J Econ Behav Organ 131 (November):198-217. https://doi.org/10.1016/j.jebo.2016.08.016

Lewis DR (2018) The perils of overconfidence: why many consumers fail to seek advice when they really should. J Financ Serv Mark 23(2):104-111. https://doi.org/10.1057/s41264-018-0048-7

Lin JT, Bumcrot C, Ulicny T, Mottola G, Kieffer C, Walsh G (2016) Investors in the United States 2016. FINRA Investor Education Foundation. http://www.usfinancialcapability.org/downloads/NFCS_2015_Inv_Survey_Full_Report.pdf

Little TD, Jorgensen TD, Lang KM, Whitney E, Moore G (2014) On the joys of missing data. J Pediatr Psychol 39(2):151-162. https://doi.org/10.1093/jpepsy/jst048

Lourenço CJS, Dellaert BGC, Donkers B (2020) Whose algorithm says so: the relationships between type of firm, perceptions of trust and expertise, and the acceptance of financial robo-advice. J Interact Mark 49(February):107-124. https://doi.org/10.1016/i.intmar.2019.10.003

Lusardi A, Mitchell OS (2007) Baby boomer retirement security: the roles of planning, financial literacy, and housing wealth. J Monet Econ, Carnegie-Rochester conference series on public policy: economic consequences of demographic change in a global economy April 21-22, 2006, 54(1):205-224. https://doi.org/10.1016/j.jmoneco.2006.12. 001

Malmendier U, Tate G (2015) Behavioral CEOs: the role of managerial overconfidence. J Econ Perspect 29(4):37-60. https://doi.org/10.1257/jep.29.4.37

Malmendier U, Taylor T (2015) On the verges of overconfidence. J Econ Perspect 29(4):3-8. https://doi.org/10.1257/jep. 29.4.3

Markovitch DG, Steckel JH, Michaut A, Philip D, Tracy WM (2015) Behavioral reasons for new product failure: does overconfidence induce overforecasts? J Prod Innov Manag 32(5):825-841. https://doi.org/10.1111/jpim.12252

Markowitz HM (1991) Foundations of portfolio theory. J Financ 46(2):469-477. https://doi.org/10.1111/j.1540-6261.1991. tb02669.x

McFadden D (1974) Conditional logit analysis of qualitative choice behavior. Front Econometr 25:105-142

Merkle C (2017) Financial overconfidence over time: foresight, hindsight, and insight of investors. J Bank Finance 84(November):68-87. https://doi.org/10.1016/j.jbankfin.2017.07.009

Miller EM (1977) Risk, uncertainty, and divergence of opinion. J Financ 32(4):1151-1168. https://doi.org/10.1111/j.15406261.1977.tb03317.x

Moore GA (2014) Crossing the chasm, 3rd edition: marketing and selling disruptive products to mainstream customers. Harper Business, New York

Muthukrishna M, Heine SJ, Toyakawa W, Hamamura T, Kameda T, Henrich J (2014) Overconfidence is universal? Depends on what you mean. Manuscript submitted for publication. http://www2.psych.ubc.ca/ henrich/pdfs/Overconfid enceManuscript2014.pdf

Nguyen TH, Han H-R, Kim MT, Chan KS (2014) An introduction to item response theory for patient-reported outcome measurement. Patient 7(1):23-35. https://doi.org/10.1007/s40271-013-0041-0

O'Neill HM, Pouder RW, Buchholtz AK (1998) Patterns in the diffusion of strategies across organizations: insights from the innovation diffusion literature. Acad Manag Rev 23(1):98. https://doi.org/10.2307/259101

Odean T (2002) Volume, volatility, price, and profit when all traders are above average. J Financ 53(6):1887-1934. https:// doi.org/10.1111/0022-1082.00078

Olsson H (2014) Measuring overconfidence: methodological problems and statistical artifacts. J Bus Res 67(8):1766-1770. https://doi.org/10.1016/j.jbusres.2014.03.002

Ortoleva P, Snowberg E (2015) Overconfidence in political behavior. Am Econ Rev 105(2):504-535. https://doi.org/10. 1257/aer.20130921

Parker AM, Stone ER (2014) Identifying the effects of unjustified confidence versus overconfidence: lessons learned from two analytic methods. J Behav Decis Mak 27(2):134-145. https://doi.org/10.1002/bdm.1787

Posada D, Buckley TR (2004) Model selection and model averaging in phylogenetics: advantages of Akaike information criterion and bayesian approaches over likelihood ratio tests. Syst Biol 53(5):793-808. https://doi.org/10.1080/10635 150490522304

Rogers EM (2010) Diffusion of innovations, 4th edn. Simon and Schuster

Sanchez C, Dunning D (2018) Overconfidence among beginners: is a little learning a dangerous thing? J Pers Soc Psychol 114(1):10-28. https://doi.org/10.1037/pspa0000102

Sironi, Paolo. 2016. FinTech Innovation: From Robo-Advisors to Goal Based Investing and Gamification. John Wiley \& Sons.

Spence AM (1981) The learning curve and competition. Bell J Econ 12(1):49-70. https://doi.org/10.2307/3003508

Statista Market Forecast (2019) Robo-advisors_United States. Statista. September 2019. https://www.statista.com/outlo ok/337/109/robo-advisors/united-states 
Stock JH, Yogo M (2002) Testing for weak instruments in linear IV regression. Working paper 284. National Bureau of Economic Research. https://doi.org/10.3386/t0284

Tse S, Wong J, Kim H (2004) A public health approach for asian people with problem gambling in foreign countries. J Gamb Issues. https://doi.org/10.4309/jgi.2004.12.13

White $\mathrm{H}$ (1980) A heteroskedasticity-consistent covariance matrix estimator and a direct test for heteroskedasticity. Econometrica 48(4):817-838. https://doi.org/10.2307/1912934

Woodyard AS, Grable JE (2018) Insights into the users of robo-advisory firms. J Financ Serv Prof 72(5):56-66

Wooldridge JM (2010) Econometric analysis of cross section and panel data. MIT Press

Xia T, Wang Z, Li K (2014) Financial literacy overconfidence and stock market participation. Soc Indic Res 119(3):12331245. https://doi.org/10.1007/s11205-013-0555-9

Yu S, Johnson S, Lai C, Cricelli A, Fleming L (2017) Crowdfunding and regional entrepreneurial investment: an application of the CrowdBerkeley database. Res Policy 46(10):1723-1737. https://doi.org/10.1016/j.respol.2017.07.008

Zha Q, Kou G, Zhang H, Liang H, Chen X, Li C-C, Dong Y (2021) Opinion dynamics in finance and business: a literature review and research opportunities. Financ Innov 6(1):44. https://doi.org/10.1186/s40854-020-00211-3

\section{Publisher's Note}

Springer Nature remains neutral with regard to jurisdictional claims in published maps and institutional affiliations.

\section{Submit your manuscript to a SpringerOpen ${ }^{\circ}$} journal and benefit from:

- Convenient online submission

- Rigorous peer review

- Open access: articles freely available online

- High visibility within the field

- Retaining the copyright to your article

Submit your next manuscript at $>$ springeropen.com 